Categoria

Trabalho Acadêmico / Artigo Completo

\title{
ANÁLISE ECONÔMICA NO USO DA ÁGUA DE PISCICULTURA NA IRRIGAÇÃO DA BANANA
}

Edilson Ramos Gomes ${ }^{1}$

Boanerges Siqueira D'albuquerque Junior²

Ramilos Rodrigues de Brito $^{3}$

RESUMO: O trabalho foi desenvolvido para determinar estratégias para a utilização de águas por meio do aproveitamento dos efluentes de piscicultura na fertirrigação da bananeira. O procedimento experimental foi locado no município de Santa Rosa-PI e pertencente à Embrapa Meio-Norte, trabalhou-se com a criação de peixes, da espécie tilápia nilótica (Oreochromis niloticus) e produção de banana FHIA 18 no $2^{\circ}$ ciclos. Os fatores estudados foram dois: o experimento com a banana FHIA 18 irrigada com água dos tanques que constou de seis lâminas de irrigação de 25, 50, 75, 100, 125 e 150\% da evapotranspiração de referência estimada pelo método de Penman-Monteith a partir de uma estação meteorológica automática. O outro fator foi a viabilidade econômica da utilização do efluente provindo da piscicultura para a irrigação da bananeira. Para lâminas de irrigação, índices de crescimento e os componentes de produção da cultura da banana estimaram-se intervalos de lâminas ideais para boa produtividade. Com relação ao reuso da água os componentes da banana não sofrem alteração em razão da utilização do efluente da piscicultura.

\footnotetext{
${ }^{1}$ Eng. Agrônomo, Mestrando em Agronomia (Irrigação e Drenagem) UNESP/FCA - SP. E-mail: edilsonevj@hotmail.com

${ }^{2}$ Eng. Agrônomo, Professor Dr. Assistente, UESPI, Picos - PI.

${ }^{3}$ Eng. Agrônomo, em Agronomia (Irrigação e Drenagem) UNESP/FCA - SP.
} 


\section{INTRODUÇÃO}

No Brasil, o uso de tecnologias modernas tem provocado mudanças no perfil técnico e econômico da agricultura. Entretanto, tem-se observado um nível acentuado de exclusão de uma parcela importante das pequenas e médias unidades produtivas, principalmente na Região Nordeste, onde se concentram os maiores índices de pobreza do país.

De acordo com dados do IBGE (2010), o Piauí apresenta população de 3,11 milhões de habitantes, dos quais aproximadamente $34 \%$ vivem no campo, em torno de 1,06 milhões. A população rural é composta, em sua maioria, por agricultores familiares com baixo poder aquisitivo e acesso limitado à tecnologia. Embora o grande contingente de trabalhadores rurais do Estado do Piauí se encontra em comunidades agrícolas, existe uma enorme carência de alternativas tecnológicas adequadas às suas condições socioeconômicas, fazendo com que os mesmos subsistam à custa de práticas extremamente ineficientes de produção agropecuária.

O Estado do Piauí caracteriza-se, de uma maneira geral, por apresentar solos com textura arenosa, possuir um considerável potencial hídrico de boa qualidade e clima favorável, que fazem dessa região um excelente polo para a produção de frutas tropicais sob-regime de irrigação. Dentre as alternativas destacam-se o cultivo de fruteiras tropicais, a bananeira umas das principais espécies cultivadas em regime de irrigação. É importante destacar que o estado do Piauí, nos últimos dez anos, vem instalando vários projetos de fruticultura irrigada para pequenos e médios produtores, a exemplo dos perímetros irrigados dos Tabuleiros Litorâneos, Platô de Guadalupe, Projeto Piloto de Fruticultura Irrigada de Santa Rosa do Piauí além de vários outros menores instalados em assentamentos com apoio da CODEVASF, Governo do Estado, INCRA, DNOCS e EMBRAPA.

A determinação de lâminas ótimas de irrigação para a bananeira proporcionará a otimização do manejo de água para essa fruteira, possibilitando a obtenção de produtividade e qualidade dos produtos economicamente satisfatórios com menos riscos de danos ambientais. Além do mais, do ponto de vista socioeconômico e ambiental, somar-se a receita proveniente da produção de frutas, a receita da produção de peixes e 
os ganhos com a redução do uso de fertilizantes químicos nos pomares. A avaliação do uso múltiplo da água, utilizando água proveniente da piscicultura, para irrigar fruteiras, requer o envolvimento com outras áreas de conhecimento voltadas à piscicultura, qualidade de água e impactos ambientais. Estudo sobre uso múltiplo e manejo de água para a bananeira são atividades capazes de promoverem a otimização dos recursos hídricos e o desenvolvimento sustentável da bananicultura irrigada nas condições semiáridas.

O objetivo da pesquisa foi determinar a eficiência de uso da água, a produtividade da bananeira FHIA 18 e avaliar a eficiência técnica e econômica do uso simultâneo da água armazenada temporariamente em reservatórios na produção de peixes.

\section{MATERIAL E MÉTODOS}

O experimento foi desenvolvido na área do Projeto Piloto de Fruticultura Irrigada no Vale do Parnaíba, localizada no Município de Santa Rosa do Piauí-PI, pertencente a Embrapa Meio-Norte. As coordenadas geográficas são: latitude $06^{\circ} 47^{\prime} 56^{\prime \prime} \mathrm{S}$, longitude $42^{\circ} 17^{\prime} 17^{\prime \prime} \mathrm{W}$ e altitude $187 \mathrm{~m}$. O solo da área experimental é classificado como Neossolo Litólico Distrófico, relevo plano, pedregroso e suave ondulado (SANTOS et al., 2006a).

Para a caracterização físico-hídrica e química do solo e da água de irrigação foram coletadas amostras das camadas de $0,00-0,20 ; 0,20-0,40$ e $0,40-0,60 \mathrm{~m}$ e nos poços tubulares destinados a fornecer água para irrigação, respectivamente.

O plantio foi realizado com espaçamento de $3 \times 3 \mathrm{~m}$ e covas abertas nas dimensões de $0,60 \times 0,60 \times 0,60 \mathrm{~m}$. As adubações e calagem foram executada de acordo com recomendação feita pela análise de solo da época, onde foram aplicados em fundação $60 \mathrm{~g}$ de FTE BR 12 (micronutrientes), $1 \mathrm{~kg}$ de superfosfato simples, $250 \mathrm{~g}$ calcário, $20 \mathrm{~L}$ de esterco e $820 \mathrm{~g}$ de cloreto de potássio por cova. Após 30 e 60 dias do plantio realizou-se adubações de cobertura com $50 \mathrm{~g}$ de uréia e $35 \mathrm{~g}$ de cloreto de potássio, aos 90 dias $70 \mathrm{~g}$ de uréia e cloreto de potássio, aos 120 dias $70 \mathrm{~g} \mathrm{e} 100 \mathrm{~g}$ respectivamente. No período de floração e frutificação foram feitas quatro aplicações com $180 \mathrm{~g} \mathrm{e} 300 \mathrm{~g}$ de uréia e cloreto de potássio e duas aplicações de superfosfato simples com $150 \mathrm{~g}$. 
A irrigação da banana foi efetuada por um sistema de microaspersão, cuja captação de água foi obtida do reservatório, com utilização de uma estação de controle composta por um conjunto moto bomba centrífuga, filtros e uma bomba injetora de fertilizante.

O delineamento experimental utilizado foi o de blocos casualizados, com seis tratamentos, (lâminas de irrigação estimadas a partir de percentuais da ETo) com quatro repetições, totalizando 24 parcelas. Cada parcela foi constituída por três linhas de plantio com 13 plantas, sendo duas bordaduras, dessas, para as medições de características morfológicas e fisiológicas, usou-se 4 plantas por parcela.

Utilizaram-se seis lâminas de irrigação baseadas em frações da evapotranspiração de referência (ETo) determinada pelo modelo de Penmam-Monteith a partir de dados coletados da estação agrometeorológica instalado na área experimental. Os tratamentos foram assim definidos: T1 - 0,25 * ETo; T2 - 0,50 * ETo; T3 - 0,75 * ETo; T4 - 1,0 *ETo; T5 - 1,25 * ETo; T6 - 1,5 * ETo.

Para realizar o monitoramento da água no perfil do solo foi instalada uma bateria com três tensiômetros por tratamento nas profundidades de 0,3, 0,5 e 0,8m.

O preparo do solo para o cultivo de peixe consta da limpeza da área e construção dos viveiros, realizados geralmente por trator de esteira, com tempo médio de trabalho de 5,5 horas por reservatório com volume de $1800 \mathrm{~m}^{3}$.

Os peixes foram estocados em reservatórios de terra revestidos no fundo por uma Iona de polietileno preta para evitar a percolação de água. Os reservatórios apresentam formato de retângulo com dimensões de $54 \times 17 \mathrm{~m}$, ficando o fundo $0,5 \mathrm{~m}$ abaixo do nível do terreno e 1,3 m acima, onde se manteve uma lâmina de 1,8 $\mathrm{m}$, com uma capacidade de armazenamento em média de $1.650 \mathrm{~m}^{3}$. Em uma das extremidades dos reservatórios onde se encontrava a bomba centrífuga existiam uma contenção de brita para que os alevinos não fossem sugados pela bomba.

Os reservatórios foram abastecidos individualmente, pela parte superior, com água proveniente de poço tubular, sendo o sistema de drenagem do mesmo realizado simultaneamente para irrigação da banana. Para aumentar a oxigenação da água dos reservatórios perfurou-se longitudinalmente a extremidade do cano de abastecimento.

Para o cálculo do custo de produção, do presente trabalho, a estrutura foi baseada no custo operacional total (COT) (MATSUNAGA et al., 1976) e no custo total de produção (CTP). O custo operacional efetivo (COE) que é formado pelo conjunto das despesas 
efetivamente desembolsadas pelo produtor foi obtido pela soma das despesas com operações mecanizadas, sendo considerados os gastos com combustíveis, reparos e manutenção, óleo lubrificante e tratorista, energia elétrica, operações manuais sendo levantada a quantidade de mão-de-obra nas diversas atividades, obtendo-se o número de homens/dia (HD) para executá-la, sendo o custo unitário conforme preços médios regionais, e para os insumos foram coletados preços médios regionais em empresas específicas. Somando ao COE os valores com os juros de custeio $(6,75 \%$ a.a. sobre metade do $\mathrm{COE}$ ), outras despesas ( $5 \%$ do $\mathrm{COE}$ ), depreciações e ferramentas, foi obtido o Custo Operacional Total (COT) e, acrescentando-se ao COT a remuneração do capital obteve-se o Custo Total de Produção (CTP).

Para calcular a lucratividade da banana FHIA 18, o preço pago ao produtor foi levantado em $\mathrm{R} \$$ (reais) na região. O preço de equilíbrio é o preço mínimo do produto que custeia a produção.

Foram estimados os seguintes indicadores:

- Receita bruta (RB) - produto da produção total (PT) em $\mathrm{kg}$ obtido no período pelo preço de venda $(P V)$, médio em $R \$$, recebido pelo produtor no período (Equação 1);

$$
R B=P T \times P V
$$

- Lucro operacional (LO) - em $\mathrm{R} \$$, obtido pela diferença entre a receita bruta (RB) em $\mathrm{R} \$$ e o custo operacional total (COT) em $\mathrm{R} \$$ (Equação 2);

$$
L O=R B-C O T
$$

- $\quad$ A receita líquida $(R L)$ - em $R \$$, obtida pela diferença entre receita bruta (RB) em $\mathrm{R} \$$ e custo total de produção (CTP), em $\mathrm{R} \$$ (Equação 3 );

$$
R L=R B-C T P
$$

- I Índice de lucratividade (operacional)(ILop) - em \%, obtido pela divisão entre o lucro operacional (LO) em $R \$$ e receita bruta (RB) em $R \$$ (Equação 4);

$$
I L o p=\left(\frac{L O}{R B}\right) \times 100
$$

- IÍndice de lucratividade (líquida)(ILI)- em \%, dado pela receita líquida (RL) em $R \$$ dividida pela receita bruta em $\mathrm{R} \$$ (Equação 5);

$$
I L l=\left(\frac{R L}{R B}\right) \times 100
$$


- $\quad$ Preço de equilíbrio (PE) - em $\mathrm{R} \$$ por $\mathrm{kg}$, obtido pela divisão do custo total de Produção (CTP) em $\mathrm{R} \$$ e a produção $(\mathrm{P})$ em $\mathrm{kg}$ (Equação 6);

$$
P E=\left(\frac{C T P}{P}\right)
$$

Esta metodologia de cálculo foi aplicada considerando a produção de peixes nos tanques destinados a armazenar água para irrigação da bananeira.

A espécie de peixe utilizada foi a Tilápia Nilótica, linhagem chitralada (O. niloticus) cujo ciclo produtivo médio é de seis meses, quando se espera que tenham atingido tamanhos adequados ao mercado (igual ou superior a $500 \mathrm{~g}$ ).

As coletas de água para análise físico-química foram realizadas mensalmente no período compreendido entre novembro de 2008 a março de 2009, ou seja, no período de cultivo do peixe, totalizando cinco coletas.

A água utilizada na irrigação foi coletada do tanque de piscicultura a uma profundidade de $30 \mathrm{~cm}$, sendo utilizado como recipiente garrafa plástica foscas, em seguida foi armazenada em freezer para no dia seguinte serem enviadas ao laboratório de análise, acondicionadas em caixa plásticas lacrada para manter a temperatura.

Determinaram-se as concentrações de cátions e ânions, utilizando as metodologias descritas por Silva (1999). As determinações das concentrações dos compostos nitrogenados - nitrito $\left(\mathrm{mg} \mathrm{L}^{-1}\right)$, nitrato $\left(\mathrm{mg} \mathrm{L}^{-1}\right)$ e amônia $\left(\mathrm{mg} \mathrm{L}^{-1}\right)$, utilizando espectrofotometria, foram realizadas conforme descrito por Golterman et al. (1978), Mackereth et al. (1978) e Koroleff (1976) respectivamente. Se determinou ortofosfato$\mathrm{PO}_{4}{ }^{2-}$ ( $\left.\mathrm{mg} \mathrm{L}^{-1}\right)$, utilizando colorimetria pelo método da Apha (1995). Fez-se ainda as determinação do $\mathrm{pH}$ (unidade padrão) e condutividade elétrica - CE (dS $\left.\mathrm{m}^{-1}\right)$. Todas as análises foram realizadas no Laboratório de Água e Solo da Embrapa Meio Norte/UEPParnaíba.

\section{RESULTADOS E DISCUSSÃO}

Os valores totais de água aplicada no $2^{\circ}$ ciclos da cultura da banana FHIA18 por microaspersão durante o período de cultivo foram divididos em três fases: no momento da fertirrigação, na irrigação e a precipitação efetiva (Tabela 1). Tabela 1. Valores totais de lâminas de água aplicadas para o $2^{\circ}$ ciclo. 


\section{$2^{\circ}$ ciclo}

\begin{tabular}{ccccc}
\cline { 2 - 5 } Tratamentos & $\begin{array}{c}\text { Fertirrigação } \\
(\mathrm{mm})\end{array}$ & $\begin{array}{c}\text { Irrigação } \\
(\mathrm{mm})\end{array}$ & $\begin{array}{c}\text { Precipitação efetiva } \\
(\mathrm{mm})\end{array}$ & $\begin{array}{c}\text { Total } \\
(\mathrm{mm})\end{array}$ \\
T1 & 83,37 & 236,15 & 292,83 & 612,3 \\
T2 & 66,23 & 472,31 & 232,63 & 771,2 \\
T3 & 57,38 & 708,46 & 201,54 & 967,4 \\
T4 & 58,61 & 944,61 & 205,84 & 1209,0 \\
T5 & 28,97 & 1180,76 & 101,75 & 1311,5 \\
T6 & 2,09 & 1416,92 & 7,35 & 1426,4 \\
\hline
\end{tabular}

Em observação aos diferentes valores de precipitação efetiva foram devido às diferenças de umidade, isto é, a capacidade de água que o volume de solo conhecido possa comportar, no caso, em relação a cada tratamento principalmente durante o período de diferenciação de lâminas.

Os valores médios de umidade encontrados foram $0,205,0,219,0,223,0,251$, $0,254,0,258 \mathrm{~cm}^{3} \mathrm{~cm}^{-3}$ para $T_{1}, T_{2}, T_{3}, T_{4}, T_{5}$ e $T_{6}$, respectivamente, indicam que as plantas da bananeira dos níveis de irrigação $T_{1}$ e $T_{6}$ se desenvolveram, respectivamente, sob menores e maiores teores de água do solo. Dessa forma, a obtenção do desenvolvimento da planta com esses valores pode ser explicada pela contribuição do período chuvoso no acúmulo de reservas no período de desenvolvimento.

A avaliação do efeito de lâminas de irrigação sobre as características de produção da bananeira foi feita no segundo ciclos de produção (Tabelas 2). Também constatou-se o efeito quadrático das lâminas de irrigação e análise de variância sobre essas características avaliadas no ciclos de produção da bananeira.

Tabela 2. Resumo da análise de variância do efeito de diferentes lâminas de irrigação sobre as características de produção da bananeira - $2^{\circ}$ ciclo.

\begin{tabular}{ccccc}
\hline Parâmetros & $\mathbf{r}^{2}$ & Cv & Média & $\begin{array}{c}\text { Níveis de } \\
\text { significância }\end{array}$ \\
\hline Produtividade $\left(\mathrm{t} \mathrm{ha}^{-1}\right)$ & 0,68 & 14,80 & 21,77 & $\mathrm{~ns}$ \\
Peso do cacho $(\mathrm{kg})$ & 0,50 & 14,82 & 19,70 & $\mathrm{~ns}$ \\
Número de pencas $\left(\mathrm{n}^{\circ}\right)$ & 0,86 & 9,98 & 9,025 & $* *$ \\
\hline
\end{tabular}


№ de banana por penca $\left(n^{\circ}\right)$

0,70

0,63

Peso de penca

Peso médio de banana ( $\mathrm{g}$ )

Peso médio da casca

Peso da polpa

Sólidos solúveis totais

$\mathrm{pH}$

Acidez total titulável ( \% )

SST/ATT

Comprimento de banana $(\mathrm{cm})$

Diâmetro de banana $(\mathrm{cm})$
0,46

0,83

0,59

0,75

0,46

0,50

0,73

0,62

0,57

\section{5,36}

16,85

15,18

17,36

17,64

10,55

3,34

13,94

14,76

6,59

7,346

\section{4,27}

2,28

158,58

51,78

106,79

17,34

ns

5,00

ns

0,39

ns

43,76

ns

14,58

ns

3,85

ns

ns

**

* S S

* significativo $(P<0,05)$; ** significativo $(P<0,01)$; ns não significativo, cv coeficiente de variação

Para a produtividade da banana no ciclo de produção 2009 (Figura 1) o valor máximo de produtividade $\left(30.051,7 \mathrm{~kg} \mathrm{ha}^{-1}\right)$ foi obtido com a aplicação de $903,12 \mathrm{~mm}$ ano${ }^{1}$ de água. A produtividade obtida neste trabalho é $40 \%$ inferior ao potencial máximo desta cultivar que é de $50 \mathrm{t} \mathrm{ha}^{-1}$ quando cultivada em boas condições de manejo (EMBRAPA, 2001), mas está próximo dos resultados encontrado por Rodrigues (2002) que encontraram produtividades de 28,6 $\mathrm{t} \mathrm{ha}^{-1}$.

Quanto a necessidade hídrica da bananeira, estima-se que o consumo anual de água seja de 1.000 a $3.430 \mathrm{~mm}$ (Lima \& Meirelles, 1986). De acordo com Doorembos e Kassam (1994), as necessidades hídricas anuais para a cultura variam de $1.200 \mathrm{~mm}$, nos trópicos úmidos, a $2.200 \mathrm{~mm}$, nos trópicos secos. Dessa forma, os valores de consumo de água observados neste trabalho estão abaixo da faixa estabelecidas por estes autores.

Santos et al. (2006b), estudando várias cultivares de banana no Sudoeste Goiano, dentre elas a FHIA 18, FHIA 01 e FHIA 21 encontraram resultados para peso de cacho de $18,41,20,86$ e $11,43 \mathrm{~kg}$, para o $2^{\circ}$ ciclo, os quais estão próximos aos encontrados nesse estudo. 


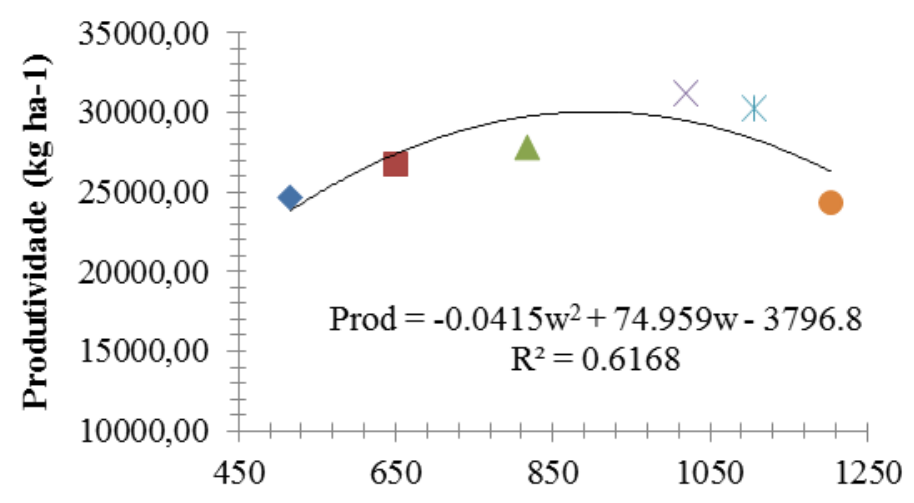

Lâminas de irrigação $\left(\mathrm{mm}^{\mathrm{ano}} \mathrm{o}^{-1}\right)$

Figura 1. Efeito de lâminas de irrigação na produtividade da banana.

O ganho de peso diário (GPD) (Tabela 3) mostra a capacidade de crescimento (em peso) dos peixes em um determinado intervalo de tempo. O ganho de peso estimado para o intervalo de tempo compreendido entre 0 e 29 dias, foi o menor $0,92 \mathrm{~g}$ quando comparados com os outros intervalos. Este pode ser explicado devido a grande variação de peso encontrado nos tanques e o período de aclimatização que pode ter sido grande. Esses valores foram aumentando na medida em que foram crescendo, e no último intervalo o DPD alcançou valores de 6,06 $\mathrm{g} \mathrm{dia}^{-1}$.

Tabela 1. Ganho de peso diário médio $\left(\mathrm{g} \mathrm{dia}^{-1}\right)$ de tilápia nilótica (O. niloticus) durante 145 dias de cultivo.

\begin{tabular}{|c|c|c|c|c|c|}
\hline & \multicolumn{5}{|c|}{ Intervalos de dias } \\
\hline & $0-29$ & $29-58$ & $58-87$ & $87-116$ & 117- 145 \\
\hline $\begin{array}{c}\text { Ganho de } \\
\text { peso diário } \\
\text { médio (GPD) } \\
\left(\mathrm{g} \mathrm{dia}^{-1}\right)\end{array}$ & 0,920 & 2,87 & 3,01 & 3,95 & 6,06 \\
\hline
\end{tabular}

Moraes (2008), em cultivo experimental de tilápia do Nilo em tanques rede, durante 84 dias, obteve valores de GPD (4,43 a 5,67 $\left.\mathrm{g} \mathrm{dia}^{-1}\right)$ menores do que os obtidos para tilápia Chitralada neste trabalho $\left(2,87\right.$ a $\left.3,01 \mathrm{~g} \mathrm{dia}^{-1}\right)$, no intervalo de 56 a 84 dias. Em experimento realizado com tilápias criadas em tanques rede, durante 130 dias, Sampaio e Braga (2005) registraram valores $\left(4,73\right.$ a $\left.5,02 \mathrm{~g} \mathrm{dia}^{-1}\right)$ bem diferente aos do presente estudo. O valor médio de GPD obtido por Carneiro et al. (1999) para tilápia Vermelha da Flórida foi o mesmo $\left(0,92 \mathrm{~g} \mathrm{dia}^{-1}\right)$, do presente estudo. 


\section{Análise econômica do sistema de produção da banana e da piscicultura}

O custo total de produção do $2^{\circ}$ ciclo da cultura da banana FHIA 18 , foi de $R \$$ $6.135,12$ (Tabela 4), sendo que esse custo observado, representando gastos apenas para esse ciclo desprezando o custo de implantação, sendo assim levando em consideração o custo de um projeto já implantado.

Tabela 2. Estimativa do custo total da produção de banana FHIA 18, por hectare, para o segundo ciclo no município de Santa Rosa do Piauí (PI), ciclo de 12 meses, com utilização de mudas de cultura de tecido.

\begin{tabular}{cc} 
Especificações & $\mathbf{2}$ ciclo \\
\cline { 2 - 2 } Custo de investimento e insumos & Valor $\mathbf{R} \$$ \\
Custos fixos & $2.236,47$ \\
Custo Operacional Efetivo & $3.000,00$ \\
Outras despesas & $5.236,47$ \\
Remuneração de capital & 375,00 \\
Custo Operacional Total & 261,80 \\
\end{tabular}

$\mathrm{Na}$ Tabela 5 são apresentadas estimativas de preços, lucratividade, receita bruta, receita líquida, preço de equilíbrio $\mathrm{kg}^{-1}$ (monetário) para o segundo ciclo da cultura da banana. Consideraram-se dois preços de venda, sendo, um no período de safra e outro no período de entressafra à nível de mercado local de produtor durante o ano de 2009. Para fins de cálculo, a produtividade da banana foi de $28 \mathrm{~T}_{\mathrm{Ta}}{ }^{-1}$ referente á média do melhor tratamento (T4).

Tabela 3. Estimativa por hectare para o segundo ciclo de preços, lucratividade e ponto de equilíbrio produção de banana FHIA 18, no município de Santa Rosa do Piauí (PI), ciclo de 12 meses. 


\begin{tabular}{|c|c|c|c|}
\hline \multirow[b]{2}{*}{ Especificações } & \multirow{2}{*}{ Unid } & \multicolumn{2}{|c|}{$2^{\circ}$ ciclo } \\
\hline & & Valor & Valor \\
\hline Preço pago pelo Kg & $\mathrm{R} \$$ & 0,50 & 0,80 \\
\hline Receita Bruta & $\mathrm{R} \$$ & $14.000,00$ & $22.400,00$ \\
\hline Custo Operacional Efetivo (COE) & $\mathrm{R} \$$ & $5.236,47$ & $5.236,47$ \\
\hline Custo Operacional Total (COT) & $\mathrm{R} \$$ & $5.873,29$ & $5.873,29$ \\
\hline Remuneração de capital & $\mathrm{R} \$$ & 261,82 & 261,82 \\
\hline Custo Total de Produção & $\mathrm{R} \$$ & $6.135,12$ & $6.135,12$ \\
\hline Receita Líquida & $\mathrm{R} \$$ & $7.864,88$ & $16.264,88$ \\
\hline Lucro Operacional & $\mathrm{R} \$$ & $8.126,71$ & $16.526,71$ \\
\hline Índice de Lucratividade (L.Op.) & $\%$ & 58,05 & 73,78 \\
\hline Índice de Lucratividade $\quad$ (R. L.) & $\%$ & 56,18 & 72,61 \\
\hline Preço de Equilíbrio Kg & $\mathrm{R} \$$ & 0,22 & 0,22 \\
\hline
\end{tabular}

Os dados demonstram que no $2^{\circ}$ ciclo de produção a receita bruta obtida foi de $R \$$ $14.000,00$ e $22.400,00$ ha $^{-1}$ e uma receita líquida de $R \$ 7.864,88$ e 16.264,88 ha para os $^{-1}$. preços praticados na Região de $\mathrm{R} \$ 0,50$ e 0,80 por quilo, no qual podemos observar que a receita líquida no primeiro ano foi de cinquenta e quatro reais mensais para o menor preço praticado no mercado, isso é devido aos investimentos ocorrido no primeiro ano, entretanto observa-se que quando o valor do fruto atinge oitenta centavos por quilo, esse passa a obter uma receita de setecentos e quarenta e cinco reais por mês.

No município estudado, os indicadores obtidos mostram que o sistema de produção da banana é uma atividade rentável, uma vez que a lucratividade obtida, considerando o custo operacional efetivo e o custo operacional total variaram de 8,89 a 63,67\% e 43,06 a $77,30 \%$ respectivamente. Esses valores estão acima dos encontrados por Silva et al., (2005) em análise semelhante a essa com banana maçã micro propagada.

No município de Santa Rosa do Piauí (PI), os indicadores obtidos mostram que o sistema de cultivo de peixe é uma atividade rentável, uma vez que a lucratividade obtida, considerando o custo operacional efetivo e o custo operacional total (Tabela 6) variou de 43,97 a $25,8 \%$ e $-50,99$ a $22,23 \%$ respectivamente, sendo esses percentuais superiores aos encontrado por Pizaia et al. (2008), realizando estudos semelhantes a esse. Para 
cobrir o custo operacional total o produtor precisa produzir $3.600 \mathrm{~kg}$ por ano de produção a partir de 6600 alevinos.

É importante ressaltar que o custo operacional total calculado considerou a despesa com o fornecimento de água, o qual para o Estado do Piauí ainda não é cobrado, pois a maioria das fontes fornecedoras de água para piscicultura é poços tubulares e/ou águas superficiais, sendo dessa forma contabilizado apenas o custo com energia elétrica.

Dos itens que compõem o custo operacional total, o mais significativo é a ração que soma quase $65 \%$ do total. Isto coloca em evidência o rigor técnico requerido na gestão da alimentação dos peixes, particularmente a composição e quantidade dos nutrientes da ração.

Estes dados mostram que aumentos dos custos dos itens mais representativos, bem como redução da produção, podem provocar mudanças dos indicadores de viabilidade econômica deste investimento.

Tabela 4. Estimativa/ano de preços, lucratividade e ponto de equilíbrio produção de banana FHIA 18, no município de Santa Rosa do Piauí (PI), com dois tanques 1ciclo e meio.

\begin{tabular}{lccc}
\hline \multicolumn{1}{c}{ Especificações } & Unid. & \multicolumn{2}{c}{$\mathbf{2}^{\mathbf{0}}$ ano } \\
\cline { 3 - 4 } & & Valor & Valor \\
\cline { 3 - 4 } & $\mathrm{R} \$$ & 3,50 & 4,5 \\
Preço pelo Kg do Peixe & $\mathrm{R} \$$ & 10668,00 & 13716,00 \\
Ruceita Bruta & $\mathrm{R} \$$ & 9802,00 & 9802,00 \\
Custo Operacional Efetivo (COE) & $\mathrm{R} \$$ & 10177,00 & 10177,00 \\
Remuneraçãonal Total (COT) & $\mathrm{R} \$$ & 490,10 & 490,10 \\
Custo Total de Produção & $\mathrm{R} \$$ & 10667,10 & 10667,10 \\
Receita Líquida & $\mathrm{R} \$$ & 0,90 & 3048,90 \\
Lucro Operacional & $\mathrm{R} \$$ & 491,00 & 3539,00 \\
Índice de Lucratividade (Lucro Operacional) & $\%$ & 4,60 & 25,80 \\
Índice de Lucratividade (Receita Líquida) & $\%$ & 0,01 & 22,23 \\
Preço de Equilíbrio Kg & $\mathrm{R} \$$ & 3,50 & 3,50 \\
\hline
\end{tabular}

Fonte: Pesquisa de Preço local 
O estudo da viabilidade econômica do cultivo de banana juntamente com o cultivo da tilápia apresentado na Tabela 7, considera os custos operacionais da banana e da piscicultura e o somatório das receitas brutas das duas atividades a fim de se obter a lucratividade das atividades realizadas de maneira consorciada. Dessa forma, os índices de lucratividade desse consórcio variaram de 179,33 a 313,61\%, para o segundo ciclo e com os dois preços praticados, o que representa uma alta rentabilidade para o produtor. Tabela 5. Estimativas consolidadas dos custos operacionais, receitas bruta e líquida e índice de lucratividade da atividade de cultivo da bananeira com o cultivo da tilápia.

Especificações do consórcio Banana versus Piscicultura

2ㅇaㅇ

maior preço menor preço

Receita Bruta (R\$)

$36116,00 \quad 24668,00$

Custo Total de Produção $(\mathrm{R} \$)$

$16802,22 \quad 16802,22$

Lucro Operacional

19313,78 7865,78

Índice de Lucratividade

$\%$

186,99

313,61

\section{CONCLUSÕES}

- As maiores produtividades e qualidade de frutos da banana FHIA 18 na região semiárida do PI foram obtidas aplicando laminas de água entre 800 e 1200 mm/ciclo.

- O reuso da água da piscicultura com a tilápia, no cultivo da banana, viabiliza a utilização dos recursos hídricos e a exploração agrícola, com a obtenção de duas receitas a partir do uso compartilhado da água, obtendo com isso, altos índices de lucratividade. 


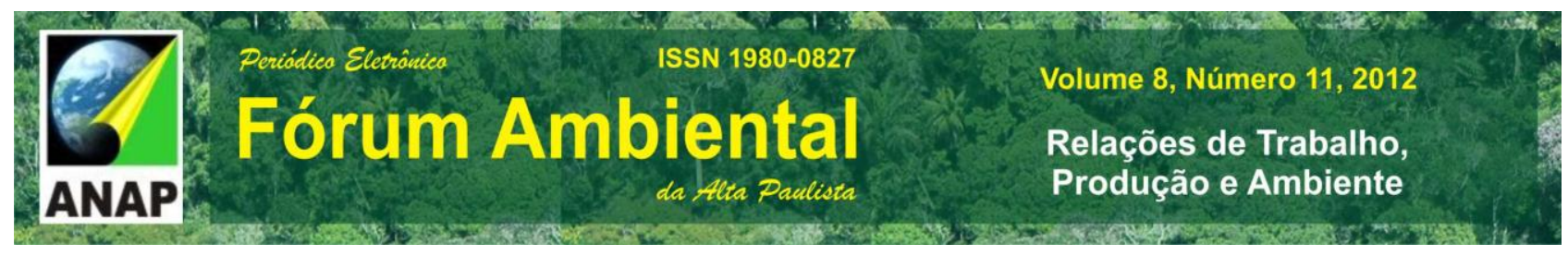

\section{REFERÊNCIAS BIBLIOGRÁFICAS}

APHA. American Public Health Association. Standard methods for the examination of water and wastewater. 19. ed., Washington: APHA, 1995. 1268p.

CARNEIRO, P. C. F.; CYRINO, J. E. P.; CASTAGNOLLI, N. Produção da tilápia vermelha da Flórida em tanques-rede. Scientia Agrícola. v.56, n.3, p. 673-679, 1999.

DOOREMBOS, J.; KASSAM, A. H. Efeito da água no rendimento das culturas, Campinas Grande: UFPB, 1994, 360p, (Estudo FAO, Irrigação e Drenagem, 33).

EMBRAPA - EMPRESA BRASILEIRA DE PESQUISA AGROPECUÁRIA, Banana FHIA 18, Disponível em http://www,cnpmf,embrapa,br/jornal/marco-2001/r\&ftecnicos, http://www, estado,estadao,com,br/editorias/2001/01/14/ger894,html, acessado em maio de 2010.

GOLTERMAN, H .J.; CLYMO, R .S.; OHNSTAD, M. A. M. Methods for physical and chemical analysis of freshwaters. Blackwell Scientia Pub., 1978. 214p.(IBP Handbook, 8).

IBGE - Instituto Brasileiro de Geografia e Estatística, Dados Gerais, Disponível em http://www.ibge.gov.br/home/estatistica/populacao/censo2010/primeiros_resultados_amostra/tabel a_brasil.shtm, Acesso em 22 de jan de 2010.

LIMA, C. A. de; MEIRELLES, M. L. Irrigação da bananeira, Informe Agropecuário, Belo Horizonte, v,12, n,133, p,61-64, 1986.

MACKERETH, F.J.H.; HERON, J.; TALLING, J.F. Water analysis: some revised methods for limnologists. London: Scient. Public., n. 36, 1978. 121p.

MATSUNAGA, Minoru; BeMELMANS, Paul F.; TOLEDO, Paulo E. N. de; DULLEY,Richard D.; OKAWA, Hiroshige; PEDROSO, Iby A. Metodologia de Custo de Produção Utilizada pelo IEA. Agricultura em São Paulo. São Paulo, ano XXIII, tomol, 1976:123-139.

MORAES, A. M. de Avaliação zootécnica e econômica do cultivo de tilápia do Nilo, Oreochromis niloticus, em tanques-rede, considerando diferentes rações comerciais. Florianópolis: Centro de Ciências Agrárias/Universidade Federal de Santa Catarina, 2008.51p. (Tese de Doutorado).

PIZAIA, M. G. A.; CAMARA, M. R. G.; SANTANA, M. A.; ALVES, R. A piscicultura no Brasil: um estudo sobre a produção e comercialização de "Oreochromis niloticus". IN: XLVI Congresso Brasileiro de Economia, Administração e Sociologia rural, 16, 2008, Rio Branco - Acre: Anais, Rio Branco: SOBER, 2008.

RODRIGUES, M. G. V.; SOUTO, R. F.; JOÃO L. P. M. Efeito da poda da última penca do cacho da bananeira prata Anã (aab) irrigada na produção de frutos no norte de Minas gerais Revista Brasileira de Fruticultura, v. 24, n. 1, p. 108-110, 2002.

SANTOS, H, G. dos; JACOMINE, P. K. T.; ANJOS, L. H. C. dos; OLIVEIRA, V. A. de; OLIVEIRA, J. B. de; COELHO, M. R.; LUMBRERAS, J. F.; CUNHA, T. J. F. Sistema brasileiro de classificação de solos, 2, ed, Rio de Janeiro: Embrapa Solos, 2006a, 306 p. 
SANTOS, S. C.; CARNEIRO, L. C.; SILVEIRA NETO, A. N. da, PANIAGO JÚNIOR, E.; FREITAS, H. G. de, PEIXOTO, C. N. Caracterização morfológica e avaliação de cultivares de bananeira resistente a sigatoka negra (mycosphaerella fijiensis morelet) no Sudoeste Goiano Revista Brasileira de Fruticultura, v. 28, n. 3, p. 449-453, 2006b.

SAMPAIO, J. M. C.; BRAGA, L. G. T. Cultivo de tilápia em tanques-rede na barragem do Ribeirão de Saloméa - Floresta Azul - Bahia. Revista Brasileira Saúde Produção Animal. v.6, n.2, p. 42$52,2005$.

SILVA, M. DE C. A. DA,; TARSITANO, M. A. A.; BOLIANI, A. C. Análises técnica e econômica da cultura da bananeira 'Maçã' (Musa spp.) na região noroeste do Estado de São Paulo. Revista Brasileira de Fruticultura. Jaboticabal,v..27, n..1. 2005.

SILVA, F.C. Manual de análises químicas de solos, plantas e fertilizantes. Brasília: Embrapa, 1999. 370p. 